\title{
Racial inequity in medical education and psychiatry
}

\author{
Bharat Sampathi, MD
}

\section{T} he ground trembled, trees shook, and voices echoed throughout the city. I looked around in awe as the dew from my breath settled on the tip of my nose, dampening my face mask. Thousands of people with varying backgrounds, together in recognition that while the arc of the moral universe is long, it cannot bend towards justice without our help. The pain, suffering, and anger of the protestors was palpable, their chants vibrating deep in my chest, all against the backdrop of the historic Los Angeles City Hall, with rows of police officers and National Guard troops on its lawn. The countless recent racially motivated attacks and murders had driven people from all walks of life to protest for an end to systemic racism. I listened to people tell stories and challenge each other to comprehend the depths of the trauma that led us to this moment, and I went home that day curious about the history of racism in medicine.

\section{Medicine's roots in slavery}

The uncomfortable truth is that medicine in America has some of its earliest roots in slavery. In an editorial in the New England Journal of Medicine, Evans et $\mathrm{al}^{1}$ wrote "Slaves provided economic security for physicians and clinical material that permitted the expansion of medical research, improvement of medical care, and enhancement of medical training." ${ }^{1}$

In the 1830s, medical schools would publicize abundant access to "black clinical subjects" as a recruitment method. The Savannah

Medical Journal, for example, proudly stated that Savannah Medical College had a Black patient census that "provided abundant clinical opportunities for studying disease." ${ }^{2}$ The dehumanization of Black people was pervasive, and while racism in medical education today may be less overt because the Black community is no longer sought after as "clinical material," discrimination continues. Ebede and Papier ${ }^{3}$ found that patients of color are extremely underrepresented in images used in medical education.

How were trainees learning to recognize clinical findings in dark-skinned patients? Was this ultimately slowing the identification and treatment of diseases in such populations?

\section{Racism in psychiatry}

In a 2020 article in Psychiatric News, American Psychiatric Association (APA) president Jeffrey Geller, MD, MPH, provided shocking insight into the history of racism in American psychiatry. ${ }^{4}$ In 1773, the Public Hospital for Persons of Insane and Disordered Minds in Williamsburg, Virginia, became the first public freestanding psychiatric hospital in British North America. ${ }^{4}$ The hospital would only accept

LET YOUR VOICE BE HEARD

CURRENT PsyChIATRY invites psychiatry residents to share their views on professional or clinical topics for publication in Residents' Voices. E-mail jbauer@mdedge.com for author guidelines.

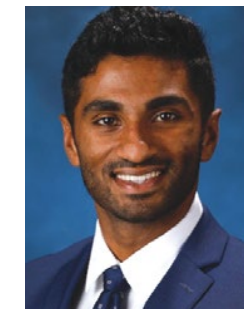

Dr. Sampathi is a PGY-2 Psychiatry Resident, Kaiser Permanente of Northern California, San Jose, California.

\section{Disclosure}

The author reports no financial relationships with any companies whose products are mentioned in this article, or with manufacturers of competing products.

doi: 10.12788/cp.0109 


\section{Clinical Point}

It is our responsibility
to confront these
biases and barriers in
medicine on a daily
basis as we strive
to create a more
equitable society

f

Discuss this article at www.facebook.com/ MDedgePsychiatry
Black patients if their admission did not interfere with the admission of White patients. Some clinicians also believed that insanity could not occur in Black people due to their "primitive nature."4 John Galt, physician head of the hospital from 1841 to 1862 and one of the APA's founding fathers, believed that Black people were "immune" to insanity because they did not experience the "mental excitement" that the free population experienced daily. Further, Benjamin Rush, considered the father of American psychiatry, was adamant that black skin itself was actually a disease, called negritude, and the only treatment involved turning a Black person white. ${ }^{4}$

The blasphemy is endless. John Calhoun, former vice president of the APA in the 1840s, stated "The African is incapable of self care and sinks into lunacy under the burden of freedom. It is mercy to him to give this guardianship and protection from mental health."

How could a population that was owned, sold, beaten, chained, raped, and ultimately dehumanized not develop mental illness? Race was weaponized by the powerful in order to deny the inalienable rights of Black people. Dr. Geller summarized these atrocities perfectly: "...during [the APA's first 40 years] ... Association members did not debate segregation by race. A few members said it shall be so, and the rest were silentsilent for a very long time."

While I train as a resident psychiatrist, I am learning the value of cultural sensitivity and the importance of truly understanding the background of all my patients in order to effectively treat mental illness. George Floyd's murder is the most recent death that has shed light on systemic racism and the challenges that are largely unique to the Black community and their mental health. I recognize that combating disparities in mental health requires an honest and often uncomfortable reckoning with the role that systemic racism has played in creating these health disparities. While the trauma inflicted by centuries of injustice cannot be corrected overnight, it is our responsibility to confront these biases and barriers in medicine on a daily basis as we strive to create a more equitable society.

\section{References}

1. Evans MK, Rosenbaum L, Malina D, et al. Diagnosing and treating systemic racism. N Engl J Med. 2020;353:274-276.

2. Washington HA. Medical apartheid: the dark history of medical experimentation on back Americans from colonial times to the present, 1st ed. Paw Prints; 2010.

3. Ebede T, Papier A. Disparities in dermatology educational resources. J Am Acad Dermatol. 2006;55(4):687-690.

4. Geller J. Structural racism in American psychiatry and APA: part 1. Published June 23, 2020. Accessed January 4, 2021. https://psychnews.psychiatryonline.org/doi/full/10.1176/ appi.pn.2020.7a18 